\title{
Low dose radioiodine therapy: A review of dosimetry and evaluation of potential shielding materials for neck collars
}

\author{
S Mubarak ${ }^{1}$, D Nanayakkara ${ }^{2}$, C Jayalath ${ }^{1}$ and V Sivakumar ${ }^{1 *}$ \\ ${ }^{I}$ Department of Physics, Faculty of Science, University of Peradeniya, Peradeniya. \\ ${ }^{2}$ Nuclear Medicine Unit, Faculty of Medicine, University of Peradeniya, Peradeniya.
}

\begin{abstract}
Radioactive Iodine $\left({ }^{131} \mathrm{I}\right)$ has become the most widely used radionuclide for the treatment of patients with thyroid cancer in Sri Lanka. This study aims to measure radiation dose rate emitted from the ${ }^{131} \mathrm{I}$ treated patients at the Nuclear Medicine Unit (NMU), University of Peradeniya, Sri Lanka and synthesise a lead-free material to be used as a shielding collar to minimize the radiation exposure to the family members and the general public. Routinely, an average activity of $1110 \mathrm{MBq}$ $(30 \mathrm{mCi})$ is administered orally to thyroid cancer patients following a thyroidectomy. A total number of 40 patients including $17.5 \%$ males and $82.5 \%$ females were monitored for radiation dose rate after administering the radioiodine. The dose rate was measured at $1.0 \mathrm{~m}$ distance from the patient's neck, after 1 hour of ${ }^{131} \mathrm{I}$ administration. The results showed moderately high dose rates (mean $50.01 \pm 11.50 \mu \mathrm{Sv} \mathrm{h}^{-1}$ ) from these patients when compared to permissible dose rates to the general public in other countries. Hence, measures should be taken to reduce the dose rates at the releasing time of the patients. Four types of shielding materials were synthesised to make a collar. The best shielding material identified was iodine incorporated silicon-based rubber with a reduction percentage of $38.48 \%$.
\end{abstract}

Keywords: ${ }^{131} \mathrm{I}$ treatment, nuclear medicine, radiation protection, shielding materials, thyroid cancer.

\section{INTRODUCTION}

According to the World Health Organization (WHO), cancer is the second leading cause of death globally and is responsible for an estimated 9.6 million deaths in 2018
(Bangkok Post, 2019; Ulinskiene et al., 2019; Sharma et al., 2020; WHO report, 2020). Approximately $70 \%$ of the deaths from cancer occur in low and middle-income countries (Sloan \& Gelband, 2007; GHEC, 2008; Bray et al., 2018; Knaul et al., 2018; WHO report, 2020). According to the American Cancer Society (ACS), thyroid cancer has seized the ninth place in worldwide rankings for incidence (Bray et al., 2018). As claimed by the International Agency for Research on Cancer under the supervision of WHO, thyroid cancer is the fifth most common cancer among Sri Lankans in 2018 (GLOBOCAN, 2018; Gunasekera et al., 2018). Also, it is the second most common cancer among women in Sri Lanka (NCCP, 2014; GLOBOCAN, 2018; Jayarajah et al., 2018).

Radioactive iodine (RAI) therapy for thyroid cancer is widely accepted and is the most frequently used treatment modality in the world (Muhammad et al., 2006). ${ }^{131} \mathrm{I}$ is administered to patients with thyroid carcinoma to ablate residual functioning thyroid tissues as well as to destroy the residual cancer cells after completion of (total or near-total) thyroidectomy (Hackshaw et al., 2007). The administered RAI is absorbed mainly by the thyroid tissues and later excreted by the renal system (Pashnehsaz et al., 2016; Haghighatafshar et al., 2018). The absorbed dose and radiation emission (dose rate) by the thyroid tissues might differ from person to person depending on many factors (Hewamanna et al., 2014).

${ }^{*}$ Corresponding author (vsiva@sci.pdn.ac.lk; (iD https://orcid.org/0000-0002-8473-767X) 
The administration of low dose RAI is relatively inexpensive and convenient for the patient with minimum side effects (Muhammad et al., 2006). However, one of the risks of using ${ }^{131} \mathrm{I}$ to treat thyroid cancer is that the patients may act as a mobile radiation source. If precautions were not taken, radiation exposure to family members, caregivers and the general public is inevitable. Thus, standard regulations are made when releasing those patients from the hospital. According to the International Atomic Energy Agency (IAEA) Safety Series No. 63 (IAEA, 2009; HERCA, 2010), patients should not be discharged from the hospital unless the ${ }^{131} \mathrm{I}$ activity is less than or equal to $1100 \mathrm{MBq}(\sim 30 \mathrm{mCi})$. At the same time, some countries follow the safety level of $400 \mathrm{MBq}$ $(\sim 11 \mathrm{mCi})$ as a measure of good practice (IAEA, 2009). Table 1 gives a list of some countries, that discharge RAI administered patients on activity basis (Brian, 2014).

Table 1: Activity based release criteria followed by some countries after RAI administration

\begin{tabular}{lc}
\hline Country & $\begin{array}{c}\text { Activity at the time of release } \\
{[\mathrm{MBq}(\mathrm{mCi})]}\end{array}$ \\
\hline China & $400(10.8)$ \\
France, United Kingdom, Poland, & $800(21.6)$ \\
Spain, New Zealand & $250(6.8)$ \\
Germany & $1100(29.7)$ \\
Malaysia, Bangladesh
\end{tabular}

Some countries use the dose rate measured at a fixed distance as a criterion for releasing patients (Zanzonico et al., 2000; Hewamanna et al., 2014). The fixed distance may vary from 1-2 $\mathrm{m}$ away from the patient, e.g. Poland measures the dose rate at $1.0 \mathrm{~m}$ from the patient whereas Germany measures at $2.0 \mathrm{~m}$ distance (Brian, 2014). However, in any case, at the time of release, ${ }^{131} \mathrm{I}$ treated patients are strictly advised on necessary precautions to be taken for the protection of whom they may come in contact with, especially pregnant women and children.

The radiation exposure to the general public from a ${ }^{131}$ I administered patient mainly depends on the patient's behaviour and understanding of radiation effects as the public is not necessarily aware of the patient's status. Considering the socio-economic conditions, extended family system, nature of the job, mode of transportation, and cultural bindings, releasing ${ }^{131} \mathrm{I}$ treated patients is a common problem in this part of the world. Currently, many countries have formed their own criteria for releasing patients after RAI therapy according to their own necessities (Brian, 2014).

Sri Lanka Atomic Energy Board (SLAEB), the regulatory body of radiation protection in Sri Lanka in compliance with the IAEA recommendations has imposed an activity-based limit of $1100 \mathrm{MBq}(\sim 30$ $\mathrm{mCi}$ ) at the discharge of ${ }^{131} \mathrm{I}$ administered patients from the hospitals (AEA, 1996). The Nuclear Medicine Unit (NMU) of the University of Peradeniya, which treats only out-patients in concurrence with the regulations of the recently established regulatory council, Sri Lanka Atomic Energy Regulatory Council (SLARC) and treats with an average ${ }^{131} \mathrm{I}$ activity of $1110 \mathrm{MBq}(30 \mathrm{mCi})$.

According to de Klerk (2000), there is a possibility for the caregivers and family members, especially toddlers and pre-schoolers, to exceed the annual maximum dose limit (Radiation Protection 97, 1998) from ${ }^{131} \mathrm{I}$ treated patients during their stay at home. For example, family members can be exposed to radiation by cross contamination while using the same bathroom or washing facilities. Usually, before Iodine administration, the patients are advised on their behaviour during the time of their isolated stay at home. While following these instructions a feasible precaution that could be taken to reduce the exposure risk is covering the neck area of the patient using a suitable shielding material.

Usage of lead collars by radioactive patients has been a known practice in developed countries over the past years, owing to the high blocking ability of lead from gamma radiation. However, due to the disadvantages such as high cost, cumbersomeness, disposal difficulties, lead toxicity, etc. currently, the usage of lead for radiation protection is replaced by other materials (Nambiar \& Yeow, 2012; Nambiar et al., 2012; Ambika \& Nagaiah, 2017). The main aspects expected in synthesising shielding materials are to be more flexible, comfortable, cost-efficient and non-toxic, so that it could be easily disposed.

In this study, an effort has been made to analyse the measured radiation dose rate at the releasing time of ${ }^{131} \mathrm{I}$ treated patients administered with an activity of $1110 \mathrm{MBq}(30 \mathrm{mCi})$. Moreover, an attempt has been made to synthesise a cost-effective, affordable and lead-free shielding material, which can be used as a collar by the patient. This collar can be used as a radiation protection shield by the ${ }^{131}$ I treated patients at the releasing time in order to minimize the exposure to the caregivers, family members and the general public. 


\section{METHODOLOGY}

\section{Dose measurement}

Ethics approval was not obtained for this study, as it does not require any extra data other than the regular data collected by the NMU, University of Peradeniya for clinical and other safety purposes. Data did not contain any identifiers, which can reveal the personal identity of the subjects. No changes in protocols were adopted for the benefit of this study.

The study used secondary data of 40 thyroid cancer patients (17.5\% males and $82.5 \%$ females) who have undergone a total or near-total thyroidectomy and were referred to the NMU of the University of Peradeniya. Patients had been administered with radioactive Iodine $\left({ }^{131} \mathrm{I}\right)$ having a mean activity of $1043.4 \mathrm{MBq}(28.2 \mathrm{mCi})$ and a median of $1036 \mathrm{MBq}(28 \mathrm{mCi})$ with a standard deviation (SD) of $61.42 \mathrm{MBq}(1.66 \mathrm{mCi})$.

Dose rates emitted from each patient after 1 hour had been recorded at $1.0 \mathrm{~m}$ distance away from the neck,

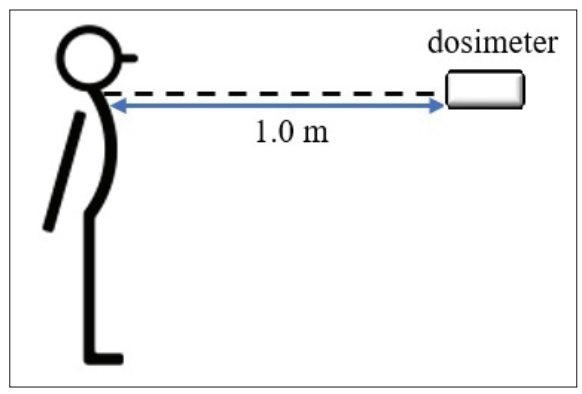

Figure 1: The figure shows the arrangement to take dose rates at the neck area while the patient was in a standing position (Figure 1), according to the IAEA protocol (IAEA, 2009). Calibrated, portable dose rate meter type - RadEye ${ }^{\mathrm{TM}}$ PRD was used to measure the dose rate in $\mu \mathrm{Sv} \mathrm{h}^{-1}$. Here, the readings of the RadEye were cross-checked with a dose rate meter (Nuclear Enterprises Portable Dose Rate Meter Type PDR 1) available at the NMU. The dose rate meter at the NMU is calibrated annually at the SLAEB. Background radiation was subtracted from the measurements.

According to the protocol followed by the NMU, patients are allowed to go home after 1 hour from the time of administration.

\section{Collar material}

Polyethylene glycol, ethylene glycol and rubber were used as matrix media for the protective collar. Locally available fillers such as bone powder, calcium and phosphate compounds and elements such as Iodine were systematically incorporated into the matrix media.

The alumina incorporated polymer sample was prepared as follows. Alumina (Sigma-Aldrich) $(1.28 \mathrm{~g})$ was vacuum dried using the vacuum oven at a temperature of $50{ }^{\circ} \mathrm{C}$ for $2 \mathrm{~h}$ and was ground well using an agate mortar and pestle. Polyethylene glycol (SigmaAldrich) (5.12 g) and ethylene glycol (Sigma-Aldrich) $(1.28 \mathrm{~g})$ dissolved in ethanol was added to a beaker along with the ground alumina and DI water. The mixture was thoroughly mixed using a magnetic stir for $2 \mathrm{~h}$ to ensure uniform dispersion of alumina in the mixture and was poured into a mold.

In order to prepare the samples with bone powder, first the chloroprene rubber (commercially available) was mixed with dichloromethane (to reduce the thickness) and a small volume was poured into a Perspex mold to get a thin layer. Then to get a composition ratio

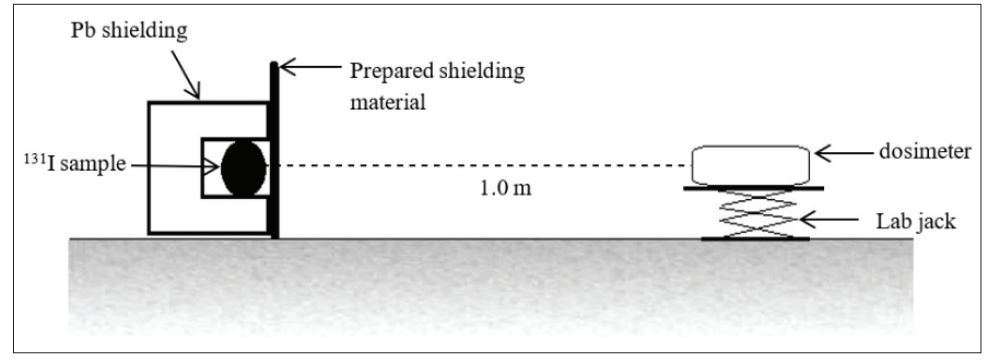

Figure 2: Experimental setup used to calculate the dose rate reduction of the shielding materials prepared 
of Ca:P:S:C equals to $6: 2: 1: 1$ (wt\%), bone powder was dusted upon the chloroprene rubber layer using a metal sieve and allowed to dry. The above-mentioned layers were repeated one after the other until the thickness of $5.0 \mathrm{~mm}$ was obtained. The bones were purchased from the local market and were powdered using a laboratory ball mill and sieved using a sieve shaker machine.

To prepare the iodine incorporated silicon rubber (Dow Corning) sample, $20 \mathrm{~mL}$ of slime-6178 base and $0.30 \mathrm{~mL}$ of catalyst-9600 (1.5\% volume of the slime) were mixed in a beaker. Iodine crystals (5 g) (99\%, C\&G chemicals) were powdered and added to the beaker. The mixture was poured into a Perspex mold and allowed to dry. In all the samples the filler to matrix medium weight radio was maintained around 1:4 ratio.

Out of the material combinations used, siliconrubber-based media incorporated with iodine powder $\left(\mathrm{I}_{2}, 99 \%, \mathrm{C} \& \mathrm{G}\right.$ chemicals) and bone powder (purchased from the local market) gave the best shielding ability. The collar was tested using a ${ }^{131} \mathrm{I}$ source while keeping the collar very close to the source and measuring the dose rate at $1.0 \mathrm{~m}$ away from the collar using the same dosimeter (Figure 2).

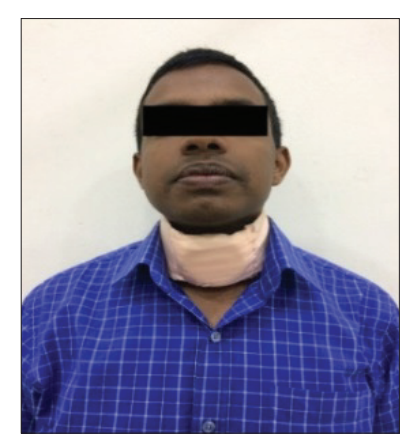

Figure 3: Prototype collar prepared from Iodine incorporated Si-rubber

\section{Usage of collar}

Figure 3 depicts the usage of a collar (not with a real patient) that contains the shielding material to cover the thyroid gland. In this prototype, the material blocks the radiation emitted from the front part of the neck. However, it is possible to make the entire collar using the same material so that it can cover the entire neck region. It must be noted that, similar to previously reported studies (Grigsby et al., 2000; Loutfi et al., 2003), testing the collar with real patients and exposure to caregivers and household members were not undertaken as it required ethical approval.

\section{RESULTS AND DISCUSSION}

\section{Dose rate readings}

Forty patients were included in the study. The study population consisted of $17.5 \%$ males and $82.5 \%$ females, ranging in age from 17 to 71 years (mean 40.3 \pm 13.16 years $)$. Mean activity of $1043.4 \mathrm{MBq}(28.2 \mathrm{mCi})$ [SD $61.42 \mathrm{MBq}(1.66 \mathrm{mCi})]{ }^{131} \mathrm{I}$ was administered to the patients. The mean dose rate measured at a $1.0 \mathrm{~m}$ distance from the patient's neck area after 1 hour of ${ }^{131} \mathrm{I}$ administration was $50.01 \mu \mathrm{Sv} \mathrm{h}^{-1}\left(\mathrm{SD} 11.50 \mu \mathrm{Sv} \mathrm{h}^{-1}\right)$ with the range 37.3-80.0 $\mu \mathrm{Sv} \mathrm{h}^{-1}$. By using the reported effective half-life of 5.5 days for ${ }^{131} \mathrm{I}$ by Hewamanna et al. (2014), the calculated mean activity after 1 hour of post administration was $1037.94 \mathrm{MBq}(28.05 \mathrm{mCi})$.

A histogram of the normalized dose rate $(\mu \mathrm{Sv} / \mathrm{h}$ $\mathrm{MBq})$ of each patient at $1.0 \mathrm{~m}$ distance at the time of discharge is given in Figure 4. The histogram shown in Figure 5 represents the fluctuation of the dose rate values $\left(\mu \mathrm{Sv} \mathrm{h} \mathrm{h}^{-1}\right)$ at the time of discharge, measured at $1 \mathrm{~m}$ distance along with dose rate limits at the discharge practiced in some countries. Also, the figure shows the deviation of the above dose rate limits with respect to the mean value of our measured dose rates. These deviations show that the mean of dose rates measured at the release of the patients at the NMU of University of Peradeniya is moderately high.

Over the past decade, total or near-total surgical removal of the thyroid gland (thyroidectomy) followed by radioactive iodine therapy for ablation of remnant thyroid cells has been the standard treatment for differentiated thyroid cancer (Hewamanna et al., 2014; Pacini et al., 2015). The main concern of using RAI is the radiation exposure risk to the caregivers and the general public due to the ionizing radiation emitted from the ${ }^{131} \mathrm{I}$ administered patients.

Previous studies conducted in Sri Lanka on radiation dose rates emitted from the ${ }^{131} \mathrm{I}$ treated patients were on in-ward patients who received high dose RAI from $3700-11100 \mathrm{MBq}(100-300 \mathrm{mCi})$ at various radiation therapy units (Hettiarachchi, 2008) and at the National Cancer Hospital in Sri Lanka (Hewamanna et al., 2014). For the first time, this study reveals the dose rates emitted from the patients who received low dose $1100 \mathrm{MBq}$ (30 mCi) RAI as out-patient basis at NMU, University of Peradeniya, Sri Lanka. 


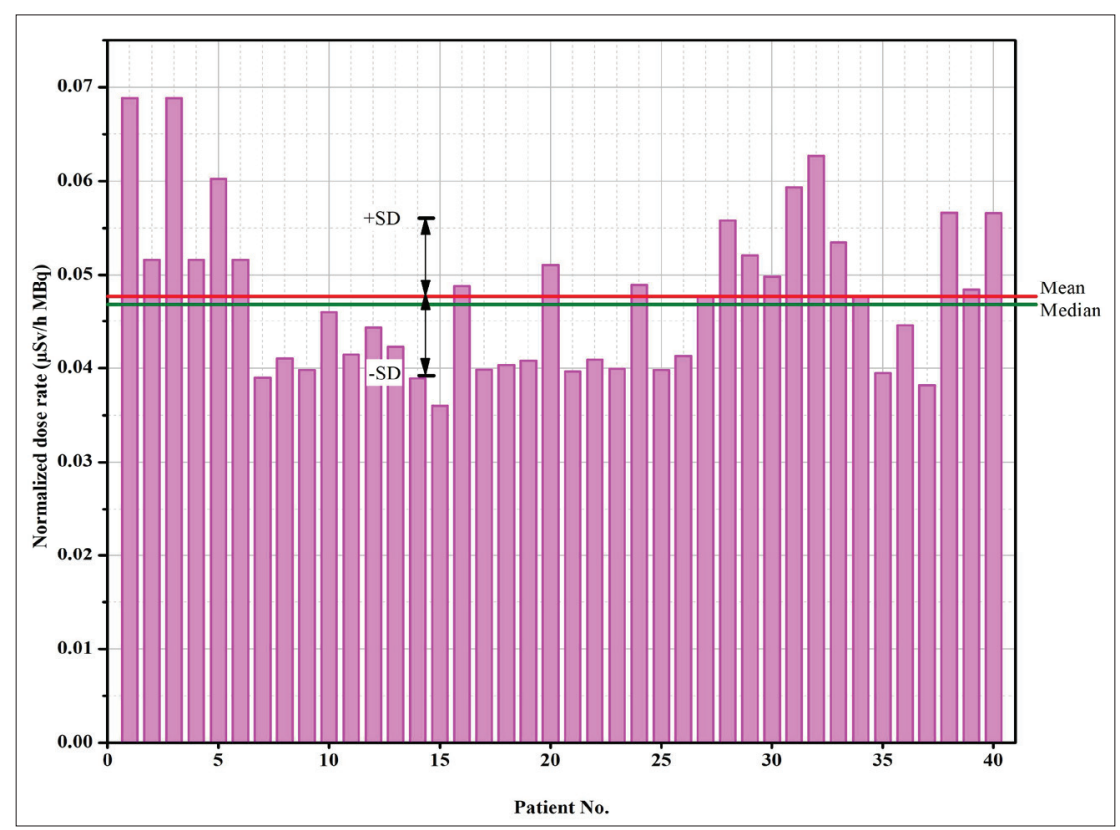

Figure 4: Histogram of the normalized dose rate $(\mu \mathrm{Sv} / \mathrm{h} \mathrm{MBq})$ of each patient measured at $1.0 \mathrm{~m}$ distance at the time of release

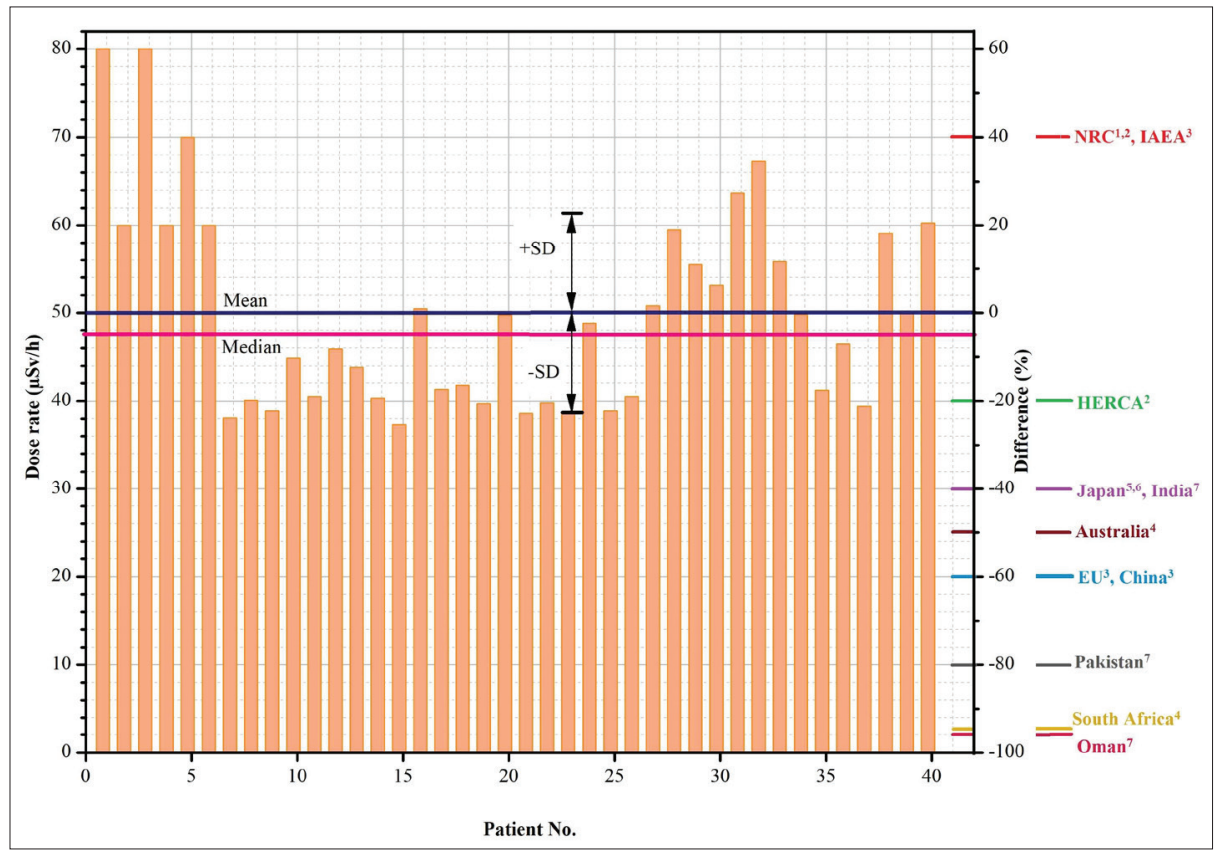

Figure 5: Measured radiation dose rates $\left(\mu \mathrm{Sv} \mathrm{h} \mathrm{h}^{-1}\right)$ emitted from each patient at $1.0 \mathrm{~m}$ distance at the time of release (on the left axis) and the percentage difference (\%) of dose limits practiced in some countries with respect to the mean of the measured dose rate (on the right axis).

${ }^{1}$ Lee et al., 2010; ${ }^{2}$ Nosheen et al., 2016; ${ }^{3 \text { Zhang }}$ et al., 2014; ${ }^{4}$ Brian, 2014; ${ }^{5}$ IAEA, 2009; ${ }^{6}$ Muhammad et al., 2006; ${ }^{7} \mathrm{Al}$-Maskery \& Bererhi, 2009 
Figure 4 proclaims a histogram of the normalized dose rate $(\mu \mathrm{Sv} / \mathrm{h} \mathrm{MBq})$ of each patient measured at $1.0 \mathrm{~m}$ distance at the time of release. Here, the emitted dose rate per unit of administered activity has been calculated for each patient involved in this study. Previous studies (Hewamanna et al., 2014) have pointed out that many variables such as the administered ${ }^{131}$ I activity, patient's gender, age, body weight, percentage of remnant thyroid cells, that differ from patient to patient affect the dose rates emitted from these patients. In our study too, one could observe the variation in the emitted dose rate from the ${ }^{131}$ I treated patients. We did not excogitate the emitted dose rate dependency on them, as it was not the scope of this study. However, Figure 4 and 5 indicates important information on radiation protection purpose considering that it is directly linked to the risk of managing these ${ }^{131} \mathrm{I}$ treated patients.

According to Hewamanna et al. (2014) some studies conducted on discharged patients administered with more than $1110 \mathrm{MBq}(30 \mathrm{mCi}){ }^{131} \mathrm{I}$ have concluded that for most of the patients, $35-75 \%$ of the ${ }^{131} \mathrm{I}$ is cleared from the body within the first 24 hours. According to Memon et al. (2017), the recommended dose rate on discharging ${ }^{131} \mathrm{I}$ treated patients to avoid unwanted radiation exposure to family members was around $20-30 \mu \mathrm{Sv} \mathrm{h}^{-1}$ at $1.0 \mathrm{~m}$ distance. Barrington et al. (1996) recommended that ${ }^{131} \mathrm{I}$ administered patients should be separated from children less than 2 years of age for at least 16 days. It has been calculated that the dose to such a child if the advice is not heeded, will be $33 \mathrm{mSv}$ which is a considerably high value compared to the annual maximum dose limit for children (1 mSv $\left.\mathrm{y}^{-1}\right)$ (Barrington et al., 1996; Radiation Protection 97, 1998; Memon et al., 2017). The same implies to the working staff and the caregivers who are being exposed, yet the maximum instructed limit for them is $5 \mathrm{mSv} \mathrm{y}^{-1}$ (Radiation Protection 97, 1998). According to the protocols followed at the National Cancer Institute (NCI) of Sri Lanka, all the patients are discharged from the hospital only when the dose rate measured at $1.0 \mathrm{~m}$ from their bodies is less than $30 \mu \mathrm{Sv} \mathrm{hr}{ }^{-1}$ (Hewamanna et al., 2014).

Complying with the regulations of SLARC, patients administered with ${ }^{131} \mathrm{I}$ are discharged with strict instructions only if the activity is less than or equal to $1110 \mathrm{MBq}$ (30 mCi) (AEA, 1996). Moreover, ${ }^{131} \mathrm{I}$ administered patients are observed 1 hour after the administration as a routine practice at the NMU premises.

It is visible that the dose rate values emitted from the ${ }^{131} \mathrm{I}$ administered patients from NMU are greater than that of most countries recommended value on discharging the patients from the hospitals (Figure 5). Thus, as a precautionary measure to this problem; we have suggested using a protective collar by the patients to reduce the emitted dose rate to a certain extent. This is in addition to the radiation protection advice given to the patients at the time of discharge.

\section{Shielding materials}

The materials synthesized incorporating different kinds of composites are presented in Table 2. Here, these sample materials were tested using a ${ }^{131} \mathrm{I}$ source $(\sim 10 \mathrm{mCi})$ that emits gamma rays at an average photon energy of $360 \mathrm{keV}$. The prepared samples were categorised into 4 main types; alumina incorporated polymers, bone composition with chloroprene rubber, bone powder with chloroprene rubber, and iodine incorporated silicon rubber. The maximum reduction percentage of radiation (1) calculated for each type of sample using equation is also shown in Table 2. Here, the measurements were taken while using the materials as a shield in front of the source (Figure 2) and without using any shield.

$$
\text { Reduction }=\frac{(\text { dose rate before shielding })-(\text { dose rate after shieding })}{\text { dose rate before shielding }} \times 100 \%
$$

Table 2: The maximum reduction percentage of different types of samples prepared

\begin{tabular}{lcc}
\hline Material & Thickness $(\mathrm{mm})$ & Maximum reduction (\%) \\
\hline lumina incorporated polymer & 4.21 & 6.75 \\
Bone composition with chloroprene rubber & 4.21 & 22.79 \\
Bone powder with chloroprene rubber & 4.02 & 30.10 \\
Iodine incorporated Si-rubber & 5.21 & 38.48 \\
\hline
\end{tabular}


In this study, the first collar material was prepared by incorporating alumina into a biocompatible polymer matrix where it gave a dose rate reduction of $6.75 \%$ while measuring at $1.0 \mathrm{~m}$ distance from the ${ }^{131} \mathrm{I}$ source (Figure 2). Commercially available chloroprene rubber incorporated with different compositions of calcium and phosphate (to obtain bone composition) gave reduction percentages that varied from $14 \%$ to $23 \%$. The maximum reduction $22.79 \%$ was obtained while using Ca: P: S: C ratio 6: 2:1: 1 wt.\% (bone composition) along with chloroprene rubber. Actual bone powder incorporated in chloroprene rubber gave a reduction percentage of $30.10 \%$. However, the major drawback of using chloroprene rubber as the matrix medium was that it became harder and rigid when the thickness was increased.

Iodine incorporated silicon rubber-based sample displayed a reduction percentage up to a maximum of $38.48 \%$. To have an inkling, the reduction percentage value was compared with the reported value of $\mathrm{He}$ et al. (2016), where an evaluation has been performed to find the shielding effectiveness of lead aprons used in nuclear medicine clinics. It has been concluded that depending on whether the aprons are really made of lead or lead equivalent thickness, the reduction percentage might vary between $19-24 \%$ for gamma rays with energy of $356 \mathrm{keV}$. Hence, considering these factors, the reduction percentage obtained for the iodine incorporated silicon rubber-based sample seems to be persuasive. This convincing reduction percentage may be due to the absorption edges of the iodine incorporated (Kane, 2009). In addition to this level of attenuating the radiation, the material is also flexible, and cost-efficient.

\section{CONCLUSION}

The results show emission of moderately high dose rates (mean $50.01 \mu \mathrm{Sv} \mathrm{h}^{-1}$ and median $47.65 \mu \mathrm{Sv} \mathrm{h}^{-1}$ with SD $11.50 \mu \mathrm{Sv} \mathrm{h}^{-1}$ ) from RAI treated patients at the time of discharge from the NMU, University of Peradeniya. In order to minimize the radiation exposure to the general public and caregivers, wearing a neck collar as a radiation shield by these patients is proposed. Among the four types of shielding materials synthesized with the aim of producing a lead-free, flexible and cost-effective collar, the best shielding material was the iodine incorporated silicon-based rubber with a reduction percentage of $38.48 \%$.

\section{Conflicts of interest}

The authors have no conflict of interest to disclose.

\section{REFERENCES}

AEA Regulations on Ionizing Radiation Protection (1996). Available at https://www.aeb.gov.lk/web/images/stories/ article/srlregulations_2000_webversion.pdf, Accessed 10 October 2019.

Al-Maskery I. \& Bererhi H. (2009). Radiation exposure levels in family members of Omani patients with thyrotoxicosis treated with radioiodine (131I) as outpatients. Sultan Qaboos University Medical Journal 9(2): 148-152.

Ambika M.R. \& Nagaiah N. (2017). Gamma shielding ability and chemical stability of polyester-based polymer composites. Indian Journal of Advances in Chemical Science S2: 23-27.

DOI: https://doi.org/10.22607/IJACS.2017.S02006

Bangkok Post Public Company Limited (2019). Cancer in the workplace: eliminating cancer anxieties. Available at https://www.bangkokpost.com/business/1762479/cancerin-the-workplace-eliminating-cancer-anxieties, Accessed 17 November 2019.

Barrington S.F., Kettle A.G., Odoherty M.J., Wells C.P., Somer E.J.R. \& Coakley A.J. (1996). Radiation dose rates from patients receiving iodine-131 therapy for carcinoma of the thyroid. European Journal of Nuclear Medicine 23(2): 123-130.

DOI: https://doi.org/10.1007/bf01731834

Bray F., Ferlay J., Soerjomataram I., Siegel R.L., Torr L.A. \& Jemal A. (2018). Global cancer statistics 2018: GLOBOCAN estimates of incidence and mortality worldwide for 36 cancers in 185 countries. CA: A Cancer Journal for Clinicians 68(6): 394-424.

DOI: https://doi.org/10.3322/caac.21492

Brian E.H. (2014). International patient release practices following iodine-131 therapy. Available at https://www. nrc.gov/docs/ML1421/ML14217A350.pdf, Accessed 25 January 2020.

de Klerk J.M.H. (2000). ${ }^{131}$ I therapy: inpatients or outpatients? Journal of Nuclear Medicine 41(11): 1876-1878.

GHEC (2008). Cancer control in low and middle-income countries. Available at https://www.cugh.org/sites/default/ files/17_Cancer_Control_In_Low_And_Middle_Income Countries_FINAL__.pdf, Accessed 10 November 2019.

GLOBOCAN (2018). Fact sheets-Sri Lanka. Available at http://gco.iarc.fr/today/data/factsheets/populations/144sri-lanka-fact-sheets.pdf, Accessed 22 November 2019.

Grigsby P.W., Siegel A., Baker S. \& Eichling J.O. (2000). Radiation exposure from outpatient radioactive iodine (131I) therapy for thyroid carcinoma. Jama 283(17): 2272. DOI: https://doi.org/10.1001/jama.283.17.2272

Gunasekera S., Seneviratne S., Wijeratne T. \& Booth C.M. (2018). Delivery of cancer care in Sri Lanka. Journal of Cancer Policy 18: 20-24.

DOI: https://doi.org/10.1016/j.jcpo.2018.10.001

Hackshaw A., Harmer C., Mallick U., Haq M. \& Franklyn J.A. (2007). 131I activity for remnant ablation in patients with differentiated thyroid cancer: a systematic 
review. The Journal of Clinical Endocrinology and Metabolism 92(1): 28-38.

DOI: https://doi.org/10.1210/jc.2006-1345

Haghighatafshar M., Banani A., Zeinali-Rafsanjani B., Etemadi Z. \& Ghaedian T. (2018). Impact of the amount of liquid intake on the dose rate of patients treated with radioiodine. Indian Journal of Nuclear Medicine 33(1): 10-13. DOI: https://doi.org/10.4103/ijnm.IJNM_90_17

He X., Zhao R., Rong L., Yao K., Chen S. \& Wei B. (2016). Answers to if the lead aprons are really helpful in nuclear medicine from the perspective of spectroscopy. Radiation Protection Dosimetry 174(4): 558-564.

DOI: https://doi.org/10.1093/rpd/ncw255

HERCA (2010). 131I therapy: Patient release criteria. Available at https://www.herca.org/docstats/Annexe\%20I HERCAOH 20110005 HERCA Release\%20criteria\%20 30062010.pdf, Accessed 18 February 2020.

Hettiarachchi M. (2008). Radiation protection in nuclear medicine: a review on present situation in Sri Lanka. Galle Medical Journal 13(1): 33-35. DOI: https://doi.org/10.4038/gmj.v13i1.892

Hewamanna R., Loganathan N. \& Perera D. (2014). Releasing thyroid cancer patients from the hospital based on dose rate measurement after 131I activity administration. Journal of the National Science Foundation of Sri Lanka 42(2): 137. DOI: https://doi.org/10.4038/jnsfsr.v42i2.6993

IAEA (2009). Safety Report Series No.63: Release of Patients After Radionuclide Therapy. Available at https://www-pub. iaea.org/MTC'D/publications/PDF/pub1417_web.pdf, Accessed 6 December 2019.

Jayarajah U., Fernando A., Prabashani S., Fernando E.A. \& Seneviratne S.A. (2018). Incidence and histological patterns of thyroid cancer in Sri Lanka 2001-2010: an analysis of national cancer registry data. BMC Cancer 18(1): 163 . DOI: https://doi.org/10.1186/s12885-018-4083-5

Kane S.A. (2009). Introduction to Physics in Modern Medicine, $2^{\text {nd }}$ edition. CRC Press, Taylor and Francis Group, USA.

Knaul F.M., Arreola-Ornelas H., Rodriguez N.M., MéndezCarniado O., Kwete X.J., Puentes-Rosas E. \& Bhadelia A. (2018). Avoidable mortality: the core of the global cancer divide. Journal of Global Oncology 4: 1-12.

DOI: https://doi.org/10.1200/jg-o.17.00190

Lee J. \& Park S. (2010). Estimation of the release time from isolation for patients with differentiated thyroid cancer treated with high-dose I-131. Nuclear Medicine and Molecular Imaging 44(4): 241-245.

DOI: https://doi.org/10.1007/s13139-010-0041-0

Loutfi I., Sakr M. \& Al-Shummari A.M. (2003). Minimizing radiation exposure from patients treated with Iodine-131 for hyperthyroidism using a lead collar: a simple and effective approach. Medical Principles and Practice 12(4): 203-207. DOI: https://doi.org/10.1159/000072284

Memon S.A., Laghari N.A., Mangi F.H., Hussain M.M. \& Nohario S.H. (2017). Isolation period of 131I administered patients at NIMRA Jamshoro Pakistan. International Journal of Radiology and Radiation Therapy 2(1): 1. DOI: https://doi.org/10.15406/ijrrt.2017.02.00011
Muhammad W., Faaruq S., Matiullah H.A. \& Khan A.A. (2006). Release criteria from hospitals of 131I thyrotoxicosis therapy patients in developing countries - case study. Radiation Protection Dosimetry 121(2): 136-139.

DOI: https://doi.org/10.1093/rpd/ncl003

Nambiar S. \& Yeow J.T.W. (2012). Polymer-composite materials for radiation protection. ACS Applied Materials \& Interfaces 4(11): 5717-5726.

DOI: https://doi.org/10.1021/am300783d

Nambiar S., Osei E.K. \& Yeow J.T.W. (2012). Polymer nanocomposite-based shielding against diagnostic X-rays. Journal of Applied Polymer Science 127(6): 49394946.

DOI: https://doi.org/10.1002/app.37980

NCCP (2014). Cancer incidence data, Sri Lanka 2014. Ministry of Health, Colombo. Available at https://www.nccp. health.gov.lk/pdf/publications/cancer_incidece/Cancer_ Incidence_in_Sri_Lanka_2014.pdf, Accessed 23 February 2020.

Nosheen F., Maseeh U.Z., Areeba Z., Unaiza Z., Rabia T. \& Wajiha S. (2016). Factors predicting early release of thyroid cancer patients from the isolation room after radioiodine-131 treatment. Asian Pacific Journal of Cancer Prevention 17: 125.

DOI: https://doi.org/10.7314/APJCP.2016.17.1.125

Pacini F., Brianzoni E., Durante C., Elisei R., Ferdeghini M., Fugazzola L., Mariotti S. \& Pellegriti G. (2015). Recommendations for post-surgical thyroid ablation in differentiated thyroid cancer: a 2015 position statement of the Italian Society of Endocrinology. Journal of Endocrinological Investigation 39: 341-347. DOI: https:// doi.org/10.1007/s40618-015-0375-7

Pashnehsaz M., Takavar A., Izadyar S., Zakariaee S.S., Mahmoudi M., Paydar R. \& Geramifar P. (2016). Gastrointestinal side effects of the radioiodine therapy for the patients with differentiated thyroid carcinoma two days after prescription. World Journal of Nuclear Medicine 15(3): 173-178. DOI: https://doi.org/10.4103/14501147.174703

Radiation Protection 97 (1998). Radiation Protection Following Iodine 131 Therapy. European Commision. Available at https://ec.europa.eu/energy/sites/ener/files/ documents/097_en.pdf, Accessed 29 January 2020

Sharma B., Parajuli P. \& Podila R. (2020). Rapid detection of urokinase plasminogen activator using flexible paper-based graphene-gold platform. Biointerphases 15(1): 011004. DOI: https://doi.org/10.1116/1.5128889

Sloan F.A. \& Gelband H. (2007). Cancer Control Opportunities in Low- and Middle-Income Countries. National Academies Press, Washington DC, USA.

DOI: https://doi.org/10.17226/11797

Ulinskiene D.L., Patasius A., Zabuliene L., Stukas R. \& Smailyte G. (2019). Increased risk of site-specific cancer in people with type 2 diabetes: a national cohort study. Endocrine Abstracts. International Journal of Environmental. Research and Public Health 17: 246. DOI: https://doi.org/10.3390/ijerph17010246 
WHO report (2020). Cancer. Available at https://www.who. int/health-topics/cancer\#tab $=t a b \_1$, Accessed 15 October 2109.

Zanzonico P.B., Siegal J.A. \& St Germain J.A. (2000). generalized algorithm for determining the time of release and the duration of post-release radiation precautions following radionuclide therapy. Health Physics 78: $648-659$.
DOI: https://doi.org/10.1097/00004032-200006000-00007 Zhang H., Jiao L., Cui S., Wang L., Tan J., Zhang G., He Y., Ruan S., Fan S. \& Zhang W. (2014). The study of external dose rate and retained body activity of patients receiving 131I therapy for differentiated thyroid carcinoma. International Journal of Environmental Research and Public Health 11(10): 10991-11003.

DOI: https://doi.org/10.3390/ijerph111010991 